\title{
Optimization problem in mathematical modeling of technological processes of economic activity on rice irrigation systems
}

\author{
Tatiana Safronova ${ }^{1}$, Stanislav Vladimirov ${ }^{1}$, Igor Prikhodko, ${ }^{1, *}$, and Alexander Sergeyev ${ }^{1}$ \\ ${ }^{1}$ Kuban State Agrarian University, 350044, 13 Kalinina Str., Krasnodar, Russia
}

\begin{abstract}
The program for maintaining food security is, first of all, a set of measures consisting of systemic, mathematically based models, taking into account the largest number of factors, signs, indicators and criteria that affect the stability of production. Stability of agricultural production directly depends not only on the degree of use of advanced technologies by the region and the economy (optimal crop rotations together with ecological adaptive technology for processing crop rotation fields, selection achievements, the use of modern mineral and organic fertilizers, the use of advanced herbicides, pesticides and others agrochemicals), technical equipment with modern domestic and/or foreign agricultural machinery, but also on the degree of optimization of using available resources on farms. The article uses a probabilistic model of the process of reducing the cost of planned reclamation measures. Within the framework of the proposed model, the optimization problem of finding the cost of activities that ensure the maximum profit for the farm has been solved. A numerical iterative algorithm for solving it has been performed. The solved problem will allow the development of calculation scenarios and control of the rice irrigation system based on mathematical modeling using modern computing facilities.
\end{abstract}

\section{Introduction}

The welfare of the state directly depends on food security. Therefore, the main goals of economic and agricultural policy pursued in Russia is to ensure optimal balanced solutions for the implementation of an increase in the volume of agricultural products which meet all domestic and foreign quality requirements [1-2].

In the Russian economy, the production of agricultural products almost completely ensures the food security of Russia. One of the main agricultural crops is rice [3-4].

The Krasnodar Territory has the best conditions for rice production and development of rice cultivation among other regions. Here is the longest duration of the warm period and the sum of temperatures. Vast territories with smooth relief and acceptable filtration properties of soils are convenient for the construction and operation of a rice irrigation system [5-6].

\footnotetext{
* Corresponding author: prihodkoigor2012@yandex.ru
} 


\section{Material and methods}

Rice yield depends on many factors: natural, reclamation, technological [7].

Assessment of natural resource potential. Rice is a thermophilic crop, for the full development of which the sum of positive air temperatures during the growing season for early maturing varieties is not less than $2500{ }^{\circ} \mathrm{C}$, mid-ripening $-2700{ }^{\circ} \mathrm{C}$ and late-ripening $3200{ }^{\circ} \mathrm{C}$. Average daily temperatures should be $13-17^{\circ} \mathrm{C}$ in the germination phase, then $18-21^{\circ} \mathrm{C}$ in the tillering phase and be within $13-19^{\circ} \mathrm{C}$ in the phase of milky and waxy ripeness [8].

Reclamation factors. The basis for obtaining high yields is soil fertility. On irrigated lands, it depends on the level of amelioration state. When cultivating rice, the topsoil is in a waterlogged state for a long time (4-6 months a year), which makes it difficult to restore fertility, reduces the efficiency of aerobic processes and activates anaerobic processes, contributes to the accumulation of toxic compounds in the soil $[9,10]$.

For the successful use of land for rice, it is necessary to carry out reclamation measures for desalination. The drainage network on rice systems should promptly divert drainage flow outside the irrigated area and maintain groundwater at specified levels [11].

Technological factors.Introduction and observance of crop rotation is the basis for high yields of rice and without herbicidal technology for growing high-quality grain. The depth of the water layer on the check significantly affects the rice yield.Maintaining an even layer of water is only possible if the surface of the check is horizontal. As criteria for the ameliorative state of rice fields from standpoint of thesoil salt regime, the following are taken: the type and degree of salinity of the meter layer of soil, the average rate of vertical filtration [12].

\section{Design of rice irrigation regime and hydronic modules of supply and discharge}

Rice irrigation systems use five types of water regime.

Let us describe, for example, the mode of shortened flooding [13].

The initial flooding, depending on the quality of the leveling the soil, is carried out to a depth of 7-10 cm, and the highest parts of the check must be covered with a layer of water of 4-5 cm, this is necessary to prevent the germination of seeds of millet weeds [14].

Later, until the onset of the period of grain waxy ripeness in rice, a layer of water of 12$15 \mathrm{~cm}$ is maintained in the checks, and then its supply is stopped [15]. On checks with a total consumption of a layer of water of $1 \mathrm{~cm}$ per day, it is completely "dumped" without dumping in 10-12 days, and the checks must dry out for the same amount of time (Figure $1)$. 


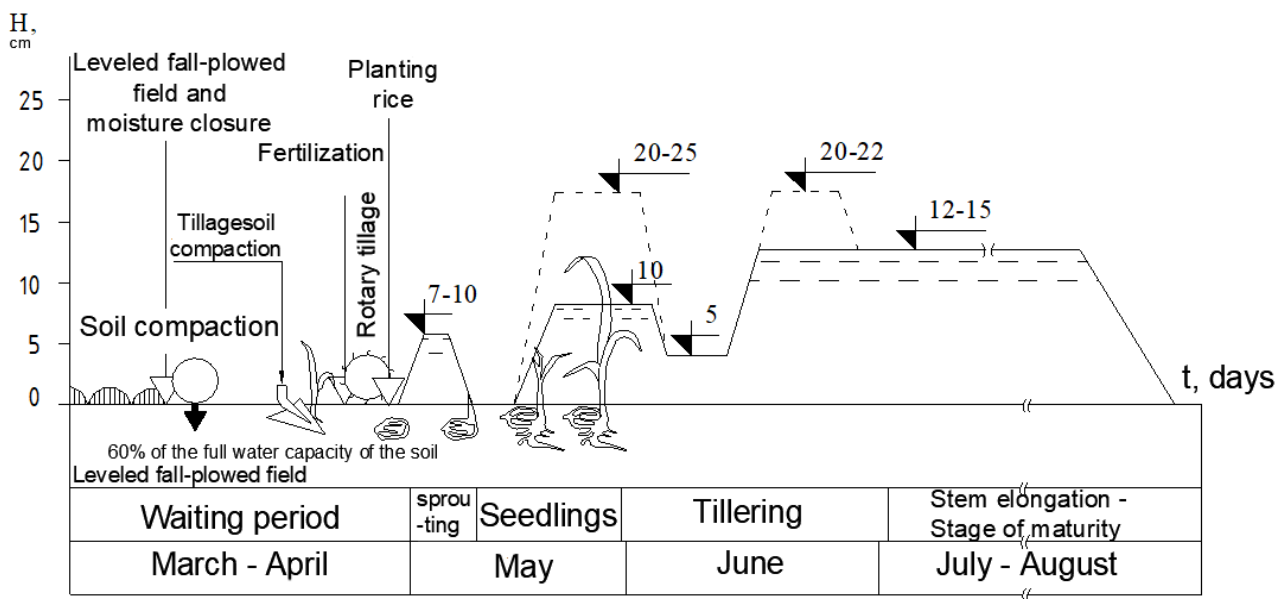

Fig. 1. Scheme of pre-sowing moisture-saving tillage and shortened flooding of the rice field

\section{Research methods}

The task of reclamation science is to study the links of the ecological chain, as well as to create economic models, which allow predicting the consequences of decisions. The most effective way to solve problems related to the water management complex is to use interrelated and optimization mathematical models [16].

In mathematical models, the cost of planned activities can be described by different functions. Previously, we considered a model of continuous change in the cost of activities. In this article, we will consider the case of a stepwise change in the cost of planned activities ( $\mathrm{mi}$ - number of possible activities). The model is shown in the figure 2 .

Let us denote $\mathrm{Si}$ - costs associated with water management in the rice system, which is generally not limited to water distribution technology. The removal of wastewater from massifs with low elevations of the earth's surface is in some cases possible only with the use of pumping stations. With its help, wastewater is reused for irrigation. The reclamation state of the serviced areas of the rice system depends on the correct operating mode of pumping stations, coordinated with fresh water supply mode.

Rice systems require two-way regulation of soil moisture, which is not only moistening or flooding, but also draining rice fields at the time of sowing and harvesting. 


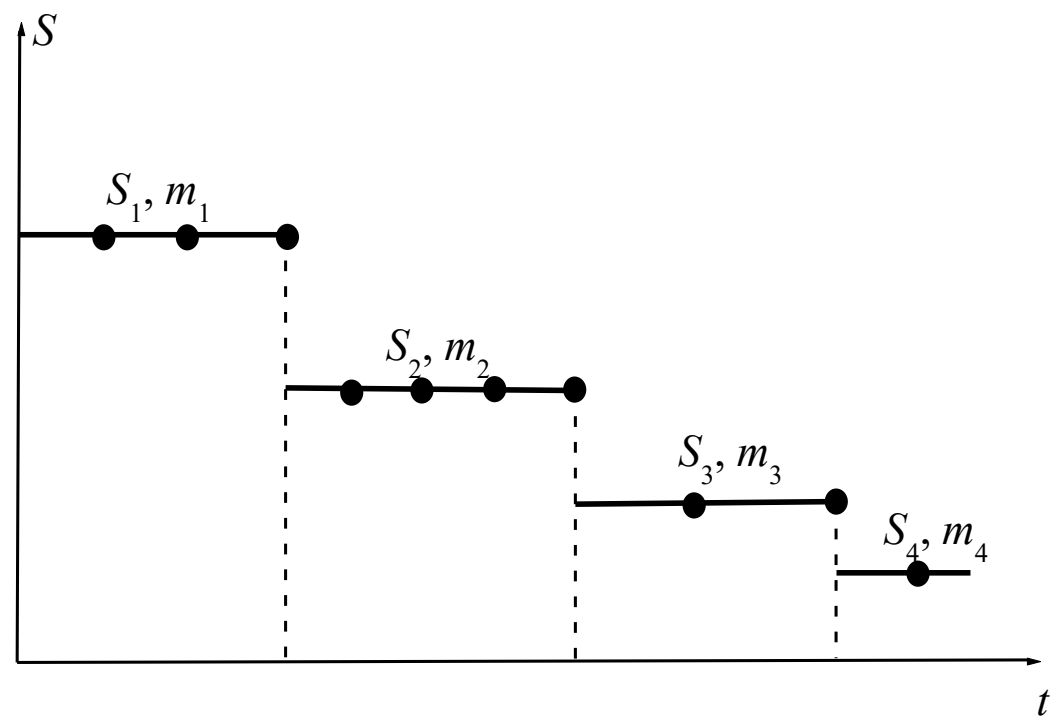

Fig. 2. Model of a stepwise change in the cost of planned reclamation activities

\section{Optimization task}

Let us denote $\mathrm{Sn}, \mathrm{Kn}$ - income and loss of the farm in the event that a satisfactory condition occurred in the n-th phase, $\mathrm{Pn}$ - the probability of the corresponding event. We will compose an expression for the mathematical expectation of the total income of the farm and we will maximize the constructed functional

$$
F=\sum_{n=1}^{\infty}\left(S_{n}-K_{n}\right)\left(1-P_{n}\right) \prod_{i=1}^{n-1} P_{i}
$$

Equating to zero the formulated expressions for the partial derivatives, we obtain the system of equations

$$
\frac{\partial F}{\partial S_{l}}=0, \quad l=\overline{1, \infty}
$$

Let us prepare an explicit form for these equations. The value (cost of the $\mathrm{i}$-th event) occurs in the term equal to

$$
\left(S_{l}-K_{l}\right)\left(1-\left(1-R\left(S_{l}\right)^{m_{l}}\right)_{i=1}^{-1} P_{i}\right.
$$

For $i=\overline{1, l-1}$ in expressions $P_{i}$ there is no $S_{l}$ magnitude. Therefore, the derivative of this term with respect to $S_{l}$ has the form

$$
\left[1-\left(1-R\left(S_{l}\right)\right)^{m_{l}}+\left(S_{l}-K_{l}\right) m_{l} R^{\prime}\left(S_{l}\right)\left(1-R\left(S_{l}\right)\right)^{m_{l}-1} \prod_{i=1}^{l-1} P_{i}\right.
$$


The terms with $n>l$ them agnitude $S_{l}$ occurs in cofactor $P_{l}=\left(1-R\left(S_{l}\right)\right)^{m_{l}}$. Write down the derivative of this factor and $\frac{\partial F}{\partial S_{l}}$

$$
\begin{gathered}
P_{l}^{\prime}=-m_{l} R^{\prime}\left(S_{l}\right)\left(1-R\left(S_{l}\right)\right)^{m_{l}-1}=-\frac{m_{l} R^{\prime}\left(S_{l}\right)}{1-R\left(S_{l}\right)} P_{l} . \\
\frac{\partial F}{\partial S_{l}}=\left[1-\left(1-R\left(S_{l}\right)\right)^{m_{l}}+\left(S_{l}-K_{l}\right) m_{l} R^{\prime}\left(S_{l}\right)\left(1-R\left(S_{l}\right)\right)^{m_{l}-1} \prod_{i=1}^{l-1} P_{i}-\right. \\
-\frac{m_{l} R^{\prime}\left(S_{l}\right)}{1-R\left(S_{l}\right)} \cdot \sum_{n=l+1}^{\infty}\left(S_{n}-K_{n}\right) \prod_{i=1}^{n-1} P_{i}\left(1-P_{n}\right) .
\end{gathered}
$$

Equate the composed expression to zero, divide by $\prod_{i=1}^{l-1} P_{i}$. As a result, we get

$$
1-\left(1-R\left(S_{l}\right)\right)^{m_{l}}+\left(S_{l}-K_{l}\right) m_{l} R^{\prime}\left(S_{l}\right)\left(1-R\left(S_{l}\right)\right)^{m_{l}-1}-\frac{m_{l} R^{\prime}\left(S_{l}\right)}{1-R\left(S_{l}\right)} Z_{l}=0
$$

where

$$
Z_{l}=\sum_{n=l+1}^{\infty}\left(S_{n}-K_{n}\right) \prod_{i=l}^{n-1} P_{i}\left(1-P_{n}\right)
$$

From expression (6) we find

$$
\frac{\left(1-R\left(S_{l}\right)\right)\left[1-\left(1-R\left(S_{l}\right)\right)^{m_{l}}\right]}{m_{l} R^{\prime}\left(S_{l}\right)}+\left(S_{l}-K_{l}\right)\left(1-R\left(S_{l}\right)\right)^{m_{l}}=Z_{l} .
$$

Similarly

$$
\frac{\left(1-R\left(S_{l+1}\right)\right)\left[1-\left(1-R\left(S_{l+1}\right)\right)^{m_{l+1}} \mid\right.}{m_{l+1} R^{\prime}\left(S_{l+1}\right)}+\left(S_{l+1}-K_{l+1}\right)\left(1-R\left(S_{l+1}\right)\right)^{m_{l+1}}=Z_{l+1}
$$

From the obtained records, we note the recurrence relation

$$
Z_{l}=\left(S_{l+1}-K_{l+1}\right) P_{l}\left(1-P_{l+1}\right)+P_{l} Z_{l+1} .
$$

and make a detailed record

$$
\begin{gathered}
\frac{\left(1-R\left(S_{l}\right)\right)\left[1-\left(1-R\left(S_{l}\right)\right)^{m_{l}}\right]}{m_{l} R^{\prime}\left(S_{l}\right)}+\left(S_{l}-K_{l}\right)\left(1-R\left(S_{l}\right)\right)^{m_{l}}= \\
=\left(S_{l+1}-K_{l+1}\right)\left(1-R\left(S_{l}\right)\right)^{m_{l}}\left[1-\left(1-R\left(S_{l+1}\right)\right)^{m_{l+1}}\right\rfloor+
\end{gathered}
$$




$$
+\left(1-R\left(S_{l}\right)\right)^{m_{l}}\left[\frac{\left(1-R\left(S_{l+1}\right)\right)\left[1-\left(1-R\left(S_{l+1}\right)\right)^{m_{l+1}}\right]}{m_{l+1} R^{\prime}\left(S_{l+1}\right)}+\left(S_{l+1}-K_{l+1}\right)\left(1-R\left(S_{l+1}\right)\right)^{m_{l+1}}\right]
$$

After transformations (dividing the resulting equality by $\left(1-R\left(S_{l}\right)\right)^{m_{l}}$ and simplifying), we obtain a recurrence relation connecting $\mathrm{Sl}$ and $\mathrm{Sl}+1$

$$
\begin{aligned}
& S_{l}-K_{l}+\frac{\left(1-R\left(S_{l}\right)\right)\left[1-\left(1-R\left(S_{l}\right)\right)^{m_{l}}\right]}{m_{l} R^{\prime}\left(S_{l}\right)\left(1-R\left(S_{l}\right)\right)^{m_{l}}}= \\
& =S_{l+1}-K_{l+1}+\frac{\left(1-R\left(S_{l+1}\right)\right)\left[1-\left(1-R\left(S_{l+1}\right)\right)^{m_{l+1}}\right]}{m_{l+1} R^{\prime}\left(S_{l+1}\right)} .
\end{aligned}
$$

Hereby: set S0 and find S1 (numerically), further received S1, find S2 etc. After that, compose an expression for the value of $\Phi$, which will depend only on S0 and numerically find the maximum of the composed function.

\section{Results and discussion}

There were selected 8 indicators of soil reclamation state in our studies:

Ground water level and salinity;

Soil pH;

Humus content;

Hydrolyzed nitrogen supply,

Availability of mobile phosphorus;

Availability of mobile potassium;

Content of aggregates:

a) $0,25-10 \mathrm{~mm}$;

b) $>0,25 \mathrm{~mm}$;

The degree and type of soil salinity.

Carrying out an ecological-adaptive complex of technological operations during the offgrowing period on five experimental fields of JSC "Chernoerkovskoye" of the Slavyansky District of the Krasnodar Territory during four years of research has shown its effectiveness, which was expressed in a decrease in the rate of alkalinization of the arable horizon; lowering the groundwater level by $0.4 \mathrm{~m}$.

\section{Conclusion}

Agricultural activity transforms natural environment. Created natural-agrarian systems determine the change in natural processes, which have developed over a long time. To reduce adverse impacts on the natural environment, it is necessary to develop quantitative criteria for ecological and economic assessment of land resources and measures taking into account the uncertainty of climatic factors. The use of quantitative recommendations will make it possible to more accurately maintain the specified optimal parameters in canals and checks and, as a result, will reduce the costs of irrigation water, improve the ameliorative condition of irrigated lands, increase the rice yield and reduce the cost of production. 
In the article, the authors emphasize the need to take into account the uncertainties of climatic factors when developing quantitative criteria for the ecological and economic assessment of land resources and propose a new methodological technique that allows a dynamic approach to operational and environmental problems. The result can be used in making management decisions.

\section{References}

1. A. Rahman, Journal of Agricultural Science and Technology, 17(4), 1071-1082 (2015)

2. O. G. Degtyareva, T. I. Safronova, I. I. Rudchenko, I. A. Prikhodko, IOP Conf. Series: Materials Science and Engineering, 698, 022015 (2019) doi:10.1088/1757899X/698/2/022015

3. N. Arbaiy, L. Pei-Chun, L.M. Shukri, C. Othman, M.H.Haikal, Advances in Intelligent Systems and Computing, 978, 15-24 (2020)

4. S. A. Vladimirov, I. A. Prikhodko, T. I. Safronova, E. F. Chebanova, E3S Web Conf. Volume 175, 2020 XIII International Scientific and Practical Conference "State and Prospects for the Development of Agribusiness - Interagromash 2020”, 12010 https://doi.org/10.1051/e3sconf/202017512010 (2020)

5. V. P. Kalinitchenko, Biogeosystem Technique, 4(10), 284-316 (2016)

6. E. Luedeling, K. D. Shepherd, C. W. Whitney, D. Lanzanova, Environmental Modelling and Software, 115, 164-175 (2019)

7. J. M. Lal, S. P. Chander, A. J. McDonald, J. H. Sahay, G. M. Kumar, A. Datta, M. Murlidhar, C. Madhu, Y. A. Kumar, D. Ritu, Soil and Tillage Research, 199, 104595 (2020)

8. I. A. Prikhodko, A. Y. Verbitsky, S. A. Vladimirov, T. I. Safronova, E3S Web Conf. Volume 175, 2020 XIII International Scientific and Practical Conference "State and Prospects for the Development of Agribusiness - Interagromash 2020”, 09011 https://doi.org/10.1051/e3sconf/202017509011 (2020)

9. L. Yahai, X. Xingxuan, G. Kailin, H. Junjie, M. Ke, Soil Biology and Biochemistry, 143, 107740 (2020)

10. E3S Web Conf. Volume 175, XIII International Scientific and Practical Conference "State and Prospects for the De-velopment of Agribusiness - Interagromash 2020", 09010 https://doi.org/10.1051/e3sconf/202017509010 (2020)

11. S. Radhika, D. Kumari, Renewable Energy, 145, 682-690 (2020)

12. H. N. Gopinath, D. Deepshikha, Environmental Science and Pollution Research, 27(2), 1533-1557 (2020)

13. H. Mooyoung, H. Shervin, B. Siamak, Ecotoxicology and Environmental Safety, 185, 109667 (2019)

14. A. K. Ashok, Y. Kuldeep, K. Nisha, J. Esha, International Journal of Recycling of Organic Waste in Agriculture, 8, 21-26 (2019)

15. S. Yaspal, M. V. Kumar, A. Sanjay, G. R. Kumar, D. Himanshu, Communications in Soil Science and Plant Analysis, 50, 2640-2654 (2019)

16. T. I. Safronova, O. G. Degtyareva, S. A. Vladimirov, I. A. rikhodko, Research Journal of Pharmaceutical, Biological and Chemical Sciences, 9(6), 1845-1852 (2018) 